\title{
THE RELATIONSHIP OF CARDIOVASCULAR AND RENAL HEMODYNAMIC FUNCTION TO SODIUM EXCRETION IN PATIENTS WITH SEVERE HEART DISEASE BUT WITHOUT EDEMA ${ }^{1,2}$
}

\author{
By WILLIAM HOLLANDER AND WALTER E. JUDSON 3 \\ (From the Robert Dareson Evans Memorial Department of Clinical Research and Preventive \\ Medicine, Massachusetts Memorial Hospitals and the Department of Medicine, \\ Boston University School of Medicine, Boston, Mass.)
}

(Submitted for publication March 19, 1956; accepted May 17, 1956)

Patients in congestive heart failure with peripheral edema are known to have an impairment of sodium excretion (1), which may persist for some time after they recover from clinical "heart failure" (2). However, little information is available concerning the sodium excretion of patients with severe heart disease and dyspnea but without a history of peripheral edema. Therefore, the present study was undertaken to investigate sodium excretion in such non-edematous cardiac patients during a moderately high sodium intake. When it was found that this group had no obvious disturbance in the renal excretion of sodium, measurements were made of their cardiovascular and renal hemodynamic functions both at rest and during exercise. These measurements were compared with similar determinations in a group of patients with severe heart disease but with peripheral edema in order to determine whether circulatory differences existed which might account for the observed differences in renal excretion of sodium.

\section{PATIENTS, METHODS AND COLLECTION OF DATA}

The first group of cardiac patients had dyspnea on exertion but no history or finding of peripheral edema although some had previously received an occasional diuretic. Most of the subjects had severe valvular heart disease and evidences of pulmonary congestion in spite of the fact that they were on maintenance doses of digitalis. None had received a diuretic for at least three weeks prior to the study. Simultaneous cardiovascular and renal hemodynamic measurements were made at rest and during exercise by methods identical to those previ-

1 Presented at the annual meeting of the American Heart Association, Chicago, Illinois, April 4, 1954.

2 This investigation was supported in part by a grant from the National Heart Institute of the National Institutes of Health, U.S.P.H.S.

3 Present address: Department of Medicine, Indiana University Medical Center, Indianapolis, Ind. ously described (3). Exercise was performed in the supine position by alternate straight leg-raising for six to nine minutes.

Within one week after these measurements were made, each patient was placed on a diet unrestricted in salt for three to five days. Following this, he was placed on a diet containing 1 gram of sodium chloride, and, in addition, was given oral tablets containing 13 grams of sodium chloride a day. This regimen was continued for 7 to 14 days during which time the patient was ambulatory but was observed for changes in symptoms or weight. Twenty-four-hour collections of urine were analyzed for sodium and chloride content at intervals of two to three days. Within a week after the completion of this study, ten of the twelve patients were studied during and after an infusion of $300 \mathrm{ml}$. of 5 per cent sodium chloride given at a rate of 10 to $12 \mathrm{ml}$. per minute. Sodium and chloride excretions were measured over the ensuing 24-hour period by taking urine collections at the end of the infusion, one hour later, and then at intervals of about six hours. Control observations were obtained by making similar studies on nine normal individuals. Urinary sodium was determined by the internal standard (lithium) flame photometer. Urinary chlorides were analyzed by the method of Wilson and Ball (4).

The second group of 10 cardiac patients were in congestive heart failure with peripheral edema. They had considerable "right sided failure" as indicated by the degree of venous distention and hepatomegaly. Most of these patients received 1 gram of salt daily in the diet, a maintenance dose of digitalis, and frequent injections of a mercurial diuretic. Cardiovascular and renal hemodynamic functions in this group were studied in the same way as the first group.

\section{RESULTS}

\section{Sodium excretion}

The data for sodium chloride balance in patients without edema of group I are shown in Table I.

The "non-edematous" patients (who had never had a history of edema) failed to gain weight or develop any change in their signs or symptoms during the entire seven to fourteen days during which they were maintained on a diet containing 14 
TABLE I

Sodium chloride excretion in a group of cardiac patients without peripheral edema *

\begin{tabular}{|c|c|c|c|c|c|c|c|}
\hline \multicolumn{2}{|c|}{ Patient } & \multirow{2}{*}{$\begin{array}{c}\text { Clinical } \\
\text { classification }\end{array}$} & \multirow{2}{*}{$\begin{array}{l}\text { Days on } \\
14 \text { gram } \\
\text { (approx.) } \\
\text { NaCl diet } \\
\end{array}$} & \multirow{2}{*}{$\begin{array}{c}\text { Changet } \\
\text { in weight } \\
\text { (pounds) } \\
\end{array}$} & \multirow{2}{*}{$\begin{array}{c}\text { Urinary } \\
\text { Na conc. } \\
(m E q . / L .) \\
\text { Average }\end{array}$} & \multirow{2}{*}{$\begin{array}{c}\text { Urinary } \mathrm{NaCl} \\
\text { excretion } \\
\text { in 24 hours } \\
\text { (gm.) } \\
\text { Average } \\
\end{array}$} & \multirow{2}{*}{$\begin{array}{l}\text { Changes in } \\
\text { signs and } \\
\text { symptoms }\end{array}$} \\
\hline Age & Sex & & & & & & \\
\hline \multicolumn{2}{|c|}{ C. $S$. } & R.H.D. & \multirow{2}{*}{13} & \multirow{2}{*}{+.50} & \multirow{2}{*}{136} & \multirow{2}{*}{13.2} & \multirow{2}{*}{ None } \\
\hline 37 & $\mathbf{M}$ & $\begin{array}{l}\text { N.S.R. } \\
\text { III D }\end{array}$ & & & & & \\
\hline \multicolumn{2}{|c|}{ A. $F$. } & R.H.D. & \multirow{2}{*}{14} & \multirow{2}{*}{-.75} & \multirow{2}{*}{145} & \multirow{2}{*}{12.8} & \multirow{2}{*}{ None } \\
\hline 32 & $\mathbf{F}$ & IV E & & & & & \\
\hline \multicolumn{2}{|c|}{ V. C. } & R.H.D. & \multirow{2}{*}{10} & \multirow{2}{*}{+1.00} & \multirow{2}{*}{94} & \multirow{2}{*}{12.6} & \multirow{2}{*}{ None } \\
\hline 32 & $\mathbf{F}$ & $\begin{array}{l}\text { A.F. } \\
\text { III D }\end{array}$ & & & & & \\
\hline \multicolumn{2}{|c|}{ S. A. } & R.H.D. & \multirow{2}{*}{12} & \multirow{2}{*}{+.25} & \multirow{2}{*}{126} & \multirow{2}{*}{12.9} & \multirow{2}{*}{ None } \\
\hline 41 & $\mathbf{F}$ & $\begin{array}{l}\text { N.S.R. } \\
\text { III D }\end{array}$ & & & & & \\
\hline \multicolumn{2}{|c|}{ J. D. } & R.H.D. & 14 & 0 & 155 & 127 & None \\
\hline 39 & $\mathbf{M}$ & AV E & 12 & 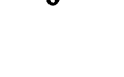 & J & 26.0 & Hoin \\
\hline & & A.S.H.D. & 7 & -125 & 137 & 134 & None \\
\hline 49 & $\mathbf{M}$ & $\begin{array}{l}\text { M.S. } \\
\text { A.F. } \\
\text { III D }\end{array}$ & 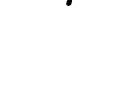 & -1.20 & 108 & 10.7 & Nuic \\
\hline & & R.H.D. & 10 & +100 & 157 & 13.5 & None \\
\hline 48 & F & III D & (o & 1800 & 100 & 10.0 & (2) \\
\hline & & Chron. Pulm. & 7 & -5 & 05 & 125 & Nan \\
\hline 47 & $\mathbf{M}$ & $\begin{array}{l}\text { Cor pulmonale } \\
\text { N.S.R. } \\
\text { IVE }\end{array}$ & 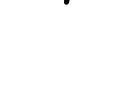 & .0 & 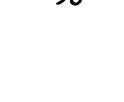 & 12.0 & Non \\
\hline & & H.C.V.D. & 10 & +125 & 105 & 140 & None \\
\hline 48 & $\mathbf{M}$ & III C & 20 & 10.20 & 100 & 17.0 & None \\
\hline & & R.H.D. & 7 & -15 & 132 & 120 & Non \\
\hline 40 & $\mathbf{M}$ & $\begin{array}{l}\text { NIS.R. } \\
\text { II C }\end{array}$ & 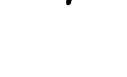 & 1.0 & 100 & 12.0 & SVIIt \\
\hline & & R.H.D. & & & & & \\
\hline 22 & F & $\begin{array}{l}\text { M.I. } \\
\text { A.I. } \\
\text { N.S.R. } \\
\text { III C }\end{array}$ & 10 & +.5 & 140 & 12.5 & None \\
\hline & & Sarcoid & 10 & 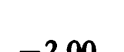 & 117 & 141 & Non \\
\hline 22 & $\mathbf{M}$ & $\begin{array}{l}\text { \& Fibrosis } \\
\text { Cor pulmonale } \\
\text { II C }\end{array}$ & 10 & -2.00 & 111 & 14.4 & Nonie \\
\hline
\end{tabular}

* Approx.-Approximately.

R.H.D.-Rheumatic Heart Disease.

N.S.R.-Normal Sinus Rhythm.

A.S.H.D.-Arteriosclerotic Heart Disease.

M.S.-Mitral Stenosis.

H.C.V.D.-Hypertensive Cardiovascular Disease M.I.-Mitral Insufficiency.

A.F.-Auricular Fibrillation.

A.I.-Aortic Insufficiency.

Sarcoid Pulm. Emph. and Fibrosis-Sarcoid Pulmonary Emphysema and Fibrosis.

$\dagger$ The difference between the weight obtained on the day preceding the 14-gram $\mathrm{NaCl}$ diet and that on the last day of the diet. 


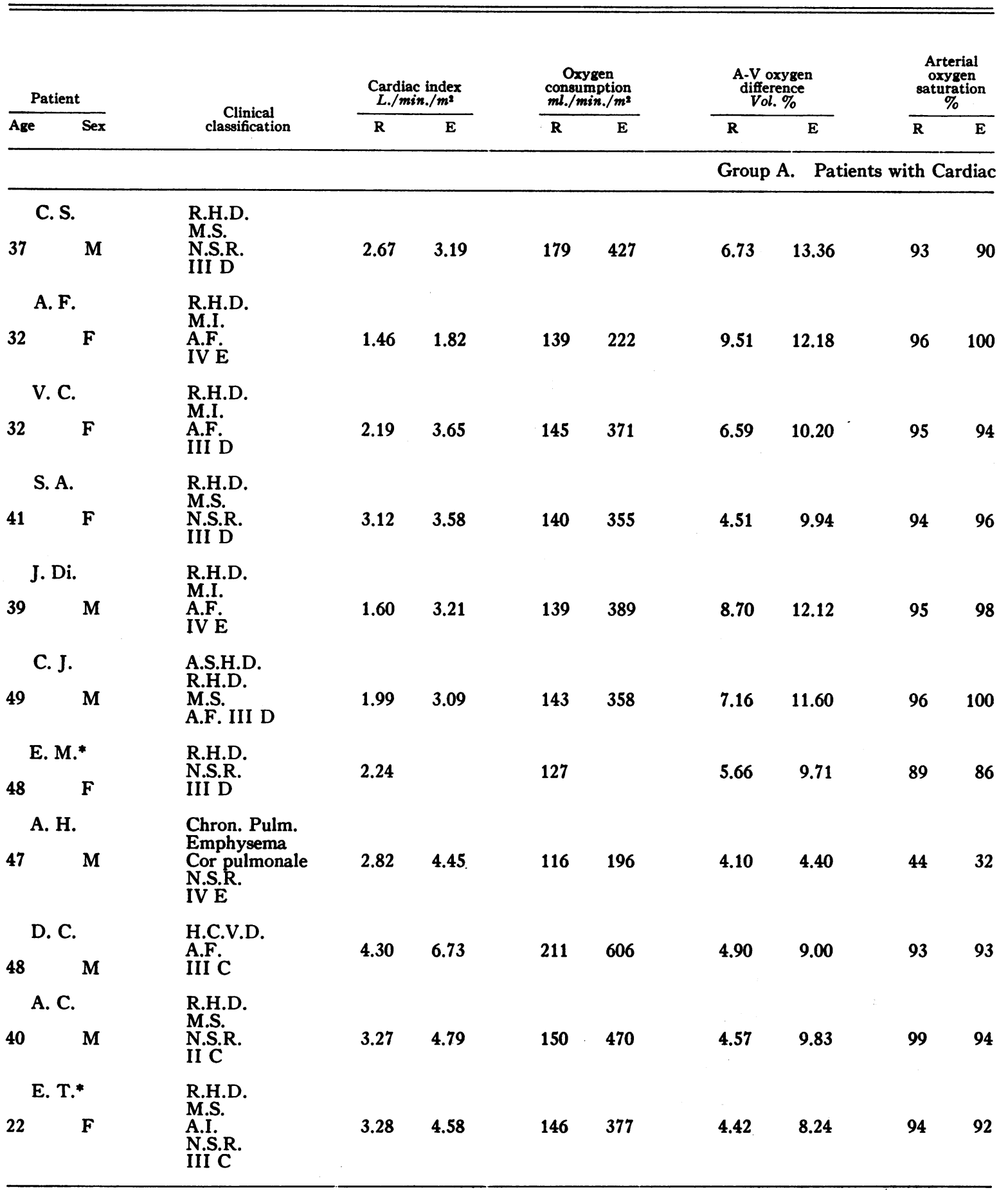

* Developed pulmonary edema during exercise.

R.H.D.-Rheumatic Heart Disease.

A.S.H.D.-Arteriosclerotic Heart Disease. H.C.V.D.-Hypertensive Cardiovascular Disease. A.F.-Auricular Fibrillation.
N.S.R.-Normal Sinus Rhythm.

M.S.-Mitral Stenosis.

M.I.-Mitral Insufficiency.

Thyroid H.D. - Thyroid Heart Disease. 
TABLE II-Contirued

\begin{tabular}{|c|c|c|c|c|c|c|c|c|c|c|c|c|c|c|c|c|}
\hline \multicolumn{13}{|c|}{ Pressures $\left(m m . H_{g}\right)$} & \multirow{3}{*}{$\begin{array}{c}\text { Pulse rate } \\
\text { Beats/ } \\
\text { min. }\end{array}$} & \multirow{3}{*}{\multicolumn{2}{|c|}{ 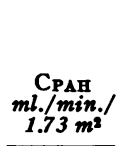 }} & \multirow{3}{*}{$\underset{\substack{\operatorname{ml} . / \min \\
1.73 \mathrm{~m}^{2}}}{\mathrm{C}_{\mathrm{N}}}$} \\
\hline \multicolumn{4}{|c|}{ Pulmonary artery } & \multirow{2}{*}{$\begin{array}{c}\text { Mean } \\
\text { pulmonary } \\
\text { capillary }\end{array}$} & \multirow{2}{*}{\multicolumn{2}{|c|}{$\begin{array}{l}\text { Right } \\
\text { ventricu- } \\
\text { lar end } \\
\text { diastolic }\end{array}$}} & \multicolumn{6}{|c|}{ Systemic arterial } & & & & \\
\hline \multirow[t]{2}{*}{$\mathbf{s}$} & D $M$ & $\mathbf{S}$ & D $\mathbf{M}$ & & & & $\mathbf{s}$ & D & $\mathbf{M}$ & $\mathbf{s}$ & D & $\overrightarrow{\mathbf{M}}$ & & & & \\
\hline & $\mathbf{R}$ & & $\mathbf{E}$ & $\bar{E}$ & $\mathbf{R}$ & $\bar{E}$ & & $\mathbf{R}$ & & & $\mathbf{E}$ & & $\mathbf{E}$ & $\mathbf{R}$ & $\mathbf{E}$ & $\mathbf{R}$ \\
\hline
\end{tabular}

Insufficiency without Peripheral Edema

$\begin{array}{llllllllllll}43 / 25 / 30 & 62 / 38 / 48 & 26 & 35 & 7 & 10 & 110 / 62 / 80 & 135 / 75 / 90 & 90 & 129 & 357 & 268\end{array}$

$\begin{array}{lllllllll}40 / 65 / & 12 & 30 & 110 / 65 / 85 & 140 / 80 / 100 & 82 & 160 & 477 & 207\end{array}$

$\begin{array}{llllllllllll}72 / 46 / 57 & 130 / 75 / 100 & 32 & 45 & 5 & 10 & 95 / 60 / 80 & 118 / 75 / 95 & 84 & 128 & 448 & 97\end{array}$

$\begin{array}{lllllllllllllll}50 / 32 / 36 & 80 / 38 / 50 & 14 & 18 & 110 / 80 / 90 & 125 / 80 / 100 & 88 & 136 & 206 & 106 & 94 & 44\end{array}$

$\begin{array}{llllllllllll}50 / 20 / 30 & 60 / 25 / 38 & 12 & 15 & 160 / 90 / 105 & 160 / 90 / 105 & 87 & 126 & 279 & 332 & 104 & 123\end{array}$

$\begin{array}{llllllllllllll}76 / 38 / 55 & 110 / 52 / 75 & 34 & 55 & 5 & 10 & 170 / 90 / 120 & 265 / 150 / 207 & 77 & 104 & 267 & 94 & 98 & 42\end{array}$

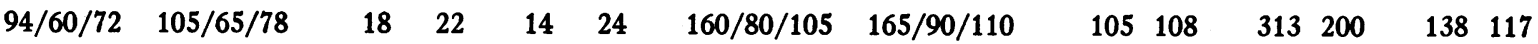

$\begin{array}{lllllllllllll}59 / 31 / 40 & 80 / 42 / 55 & 27 & 13 & 19 & 204 / 84 / 135 & 260 / 114 / 180 & 84 & 120 & 250 & 184 & 76 & 59\end{array}$

$\begin{array}{lllllllllllllll}45 / 35 / 40 & 90 / 60 / 68 & 30 & 48 & 5 & 20 & 138 / 80 / 100 & 140 / 80 / 100 & 78 & 138 & 268 & 140 & 76 & 54\end{array}$

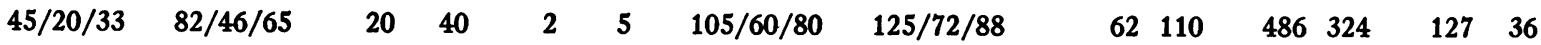

A.I.-Aortic Insufficiency.

C.P.-Cor pulmonale.

A.S.-Aortic Stenosis.

P.E.-Pulmonary Emphysema.
Chron. Pulm. Emphysema-Chronic Pulmonary Emphysema.

Sarcoid Pulm. Emphysema and Fibrosis-Sarcoid Pulmonary Emphysema and Fibrosis. 
TABLE II-Continued

\begin{tabular}{|c|c|c|c|c|c|}
\hline Patient & & $\begin{array}{l}\text { Cardiac index } \\
L . / \min . / m^{2}\end{array}$ & $\begin{array}{c}\text { Oxygen } \\
\text { consumption } \\
m l . / m i n . / m^{2}\end{array}$ & $\begin{array}{c}\text { A-V oxygen } \\
\text { difference } \\
\text { Vol. \% }\end{array}$ & $\begin{array}{c}\text { Arterial } \\
\text { oxygen } \\
\text { saturation } \\
\%\end{array}$ \\
\hline Sex & classification & $\mathbf{E}$ & $\mathbf{E}$ & $\mathbf{R}$ & $\mathbf{R}$ \\
\hline
\end{tabular}

Group A. Patients with Cardiac Insufficiency

\begin{tabular}{|c|c|c|c|c|c|c|c|c|c|c|}
\hline \multicolumn{2}{|c|}{ M. M. } & \multirow{2}{*}{$\begin{array}{l}\text { Sarcoid } \\
\text { Pulm. Emph. } \\
\text { and fibrosis } \\
\text { C.P. II C }\end{array}$} & \multirow[b]{2}{*}{3.05} & \multirow[b]{2}{*}{5.33} & \multirow[b]{2}{*}{154} & \multirow[b]{2}{*}{368} & \multirow[b]{2}{*}{5.06} & \multirow[b]{2}{*}{6.90} & \multirow[b]{2}{*}{87} & \multirow[b]{2}{*}{87} \\
\hline 22 & $\mathbf{M}$ & & & & & & & & & \\
\hline
\end{tabular}

Group B. Patients with Cardiac

\begin{tabular}{|c|c|c|c|c|c|c|c|c|c|c|}
\hline \multicolumn{2}{|c|}{ F.A. } & \multirow{2}{*}{$\begin{array}{l}\text { A.S.H.D. } \\
\text { A.F. } \\
\text { III D }\end{array}$} & \multirow{2}{*}{2.10} & \multirow{2}{*}{2.46} & \multirow{2}{*}{122} & \multirow{2}{*}{266} & \multirow{2}{*}{5.78} & \multirow{2}{*}{10.79} & \multirow{2}{*}{97} & \multirow{2}{*}{98} \\
\hline 61 & $\mathbf{F}$ & & & & & & & & & \\
\hline \multicolumn{2}{|c|}{ M. R. } & $\begin{array}{l}\text { H.C.V.D. } \\
\text { N.S.R. }\end{array}$ & \multirow{2}{*}{1.46} & & \multirow[t]{2}{*}{167} & & \multirow{2}{*}{11.40} & & \multirow[t]{2}{*}{95} & \\
\hline 39 & $\mathbf{M}$ & IV E & & & & & & & & \\
\hline \multicolumn{2}{|c|}{ R. A. } & H.C.V.D. & \multirow{2}{*}{2.40} & \multirow{2}{*}{3.50} & \multirow{2}{*}{176} & \multirow{2}{*}{395} & \multirow{2}{*}{7.32} & \multirow{2}{*}{11.13} & \multirow{2}{*}{94} & 92 \\
\hline 54 & $\mathbf{M}$ & IV D & & & & & & & & \\
\hline \multicolumn{2}{|c|}{ L. G. } & \multirow{2}{*}{$\begin{array}{l}\text { R.H.D. } \\
\text { A.S. } \\
\text { N.S.R. } \\
\text { III C }\end{array}$} & \multirow[b]{2}{*}{1.97} & \multirow[b]{2}{*}{2.97} & \multirow[b]{2}{*}{163} & \multirow[b]{2}{*}{312} & \multirow[b]{2}{*}{8.30} & \multirow[b]{2}{*}{10.51} & \multirow[b]{2}{*}{96} & \\
\hline 36 & $\mathbf{F}$ & & & & & & & & & \\
\hline \multicolumn{2}{|c|}{ C. $\mathbf{M}$. } & $\begin{array}{l}\text { Thyroid H.D. } \\
\text { A.F. }\end{array}$ & \multirow{2}{*}{4.62} & & 205 & & 4.44 & & 93 & \\
\hline 42 & $\mathbf{F}$ & III C & & & & & & & & \\
\hline & & $\begin{array}{l}\text { R.H.D. } \\
\text { M.S. }\end{array}$ & & & & & & & & \\
\hline 42 & $\mathbf{F}$ & AV & 2.10 & 2.27 & 216 & 315 & 10.13 & 13.89 & 88 & 90 \\
\hline & & $\begin{array}{l}\text { R.H.D. } \\
\text { M.S. }\end{array}$ & & & & & & & & \\
\hline 45 & $\mathbf{M}$ & $\begin{array}{l}\text { A.F. } \\
\text { III C }\end{array}$ & 2.74 & 4.06 & 158 & 391 & 5.76 & 9.65 & 93 & 88 \\
\hline & & R.H.D. & & & & & & & & \\
\hline 40 & $\mathbf{M}$ & $\begin{array}{l}\text { and M.S.' } \\
\text { A.F. III D }\end{array}$ & 2.38 & & 161 & & 6.76 & & 95 & \\
\hline & & P.E. & & & & & & & & \\
\hline 56 & $\mathbf{M}$ & IV.S.R. & 3.49 & 3.84 & 154 & 283 & 4.42 & 7.37 & 75 & 67 \\
\hline & & Silicosis & & & & & & & & \\
\hline 66 & $\mathbf{M}$ & $\begin{array}{l}\text { N.S.R. } \\
\text { III D }\end{array}$ & 3.65 & 3.50 & 137 & 215 & 3.75 & 6.12 & 52 & 51 \\
\hline
\end{tabular}


TABLE II-Continued

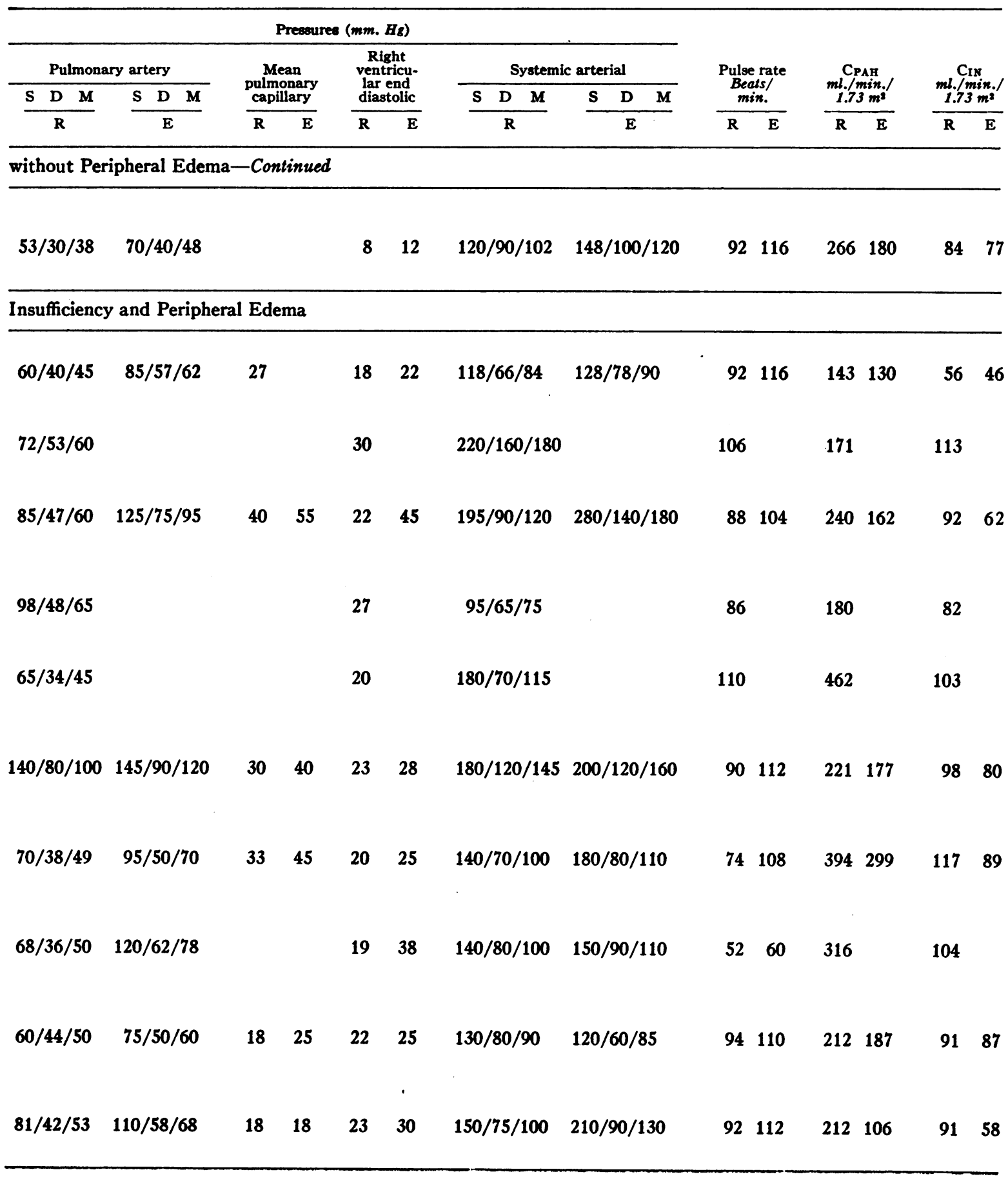




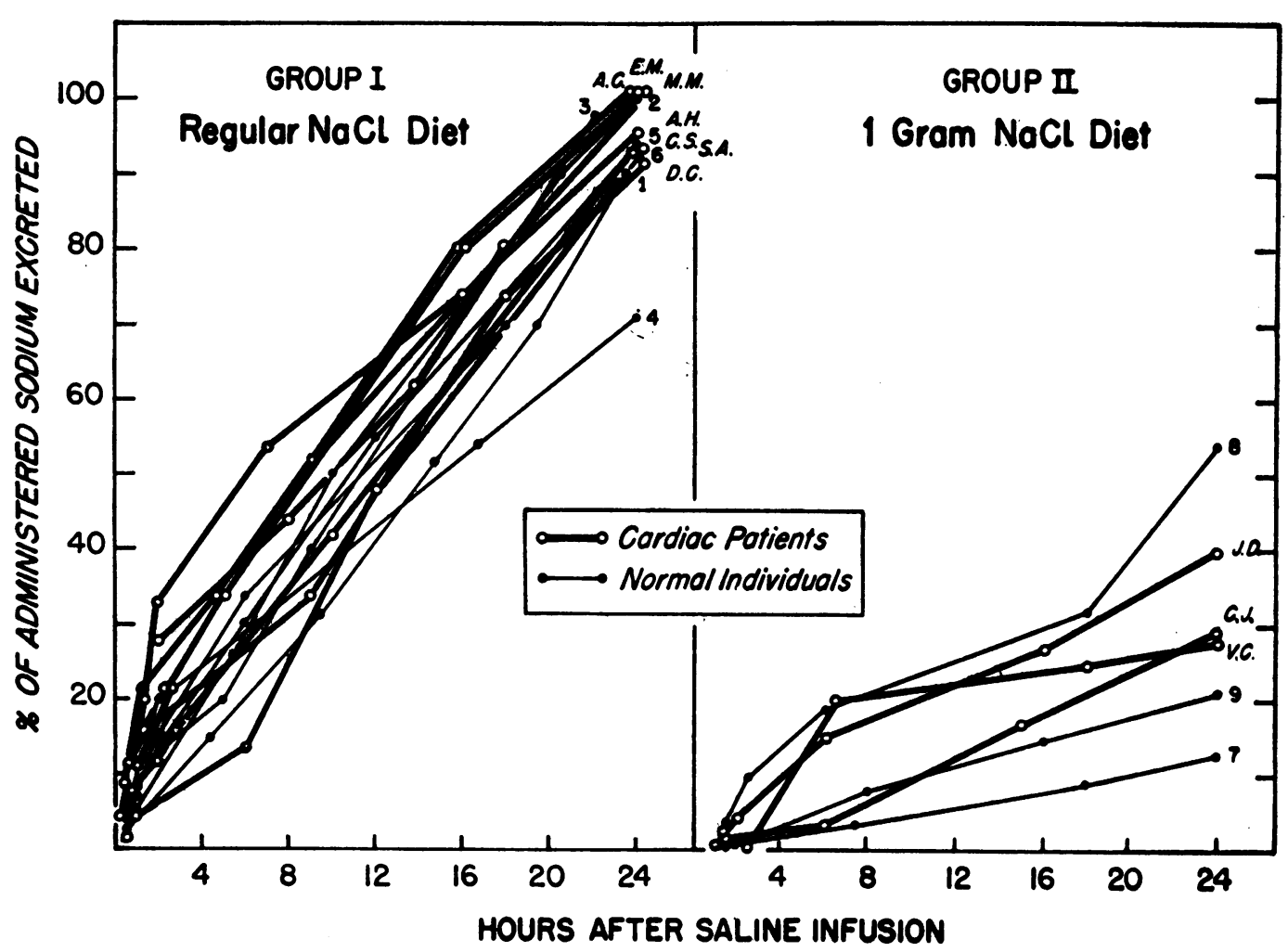

Fig. 1. Urinary Excretion of Sodium Following the Infusion of 300 ml. of 5 Per Cent Saline

grams of sodium chloride daily. The 24 -hour urinary sodium excretion showed good concentration and a high recovery of the ingested salt, averaging 93 per cent for the group. All except patients A. F., S. A., C. J., and A. H. were followed carefully on an unrestricted salt diet for at least three months following this study and they continued to be edema free and showed no change in cardiac symptoms or signs.

Figure 1 shows graphically the excretion of sodium in this group following the infusion of $300 \mathrm{ml}$. of 5 per cent sodium chloride. Seven of the ten patients, like the normal controls, showed no delay in the excretion of sodium including even patient E. M. who developed cardiac asthma during the infusion. The three remaining patients, one of whom (V. C:) also developed acute pulmonary edema during the saline infusion, had previously been on a diet restricted in sodium and all three had a delay in excretion of sodium. This, however was comparable to that observed in three normal individuals who had likewise been on a limited sodium intake.

\section{Hemodynamic functions}

The cardiovascular and renal hemodynamic functions in this group of non-edematous cardiac patients are given in Table II for comparison with those in the edematous cardiac patients. A statistical analysis of the differences between these two groups is given in Table III.

Cardiac index and oxygen consumption. At rest the cardiac index was abnormally low and not significantly different in the two cardiac groups. During exercise the group without edema had a higher mean cardiac index (by $0.81 \mathrm{~L}$. per min. per $\mathrm{m}^{2}$ ) than the group with edema but this difference was not statistically significant. At rest and during exercise, the oxygen consumption and $\mathrm{A}-\mathrm{V} \mathrm{O}$ difference likewise were not significantly different in the two groups. In response to exercise both groups had significant rises in cardiac index. The increase in this function, however, was significantly greater in the group without edema than the group with edema. This difference between the groups in response to exercise was not associated with a significantly different arteriovenous oxygen 


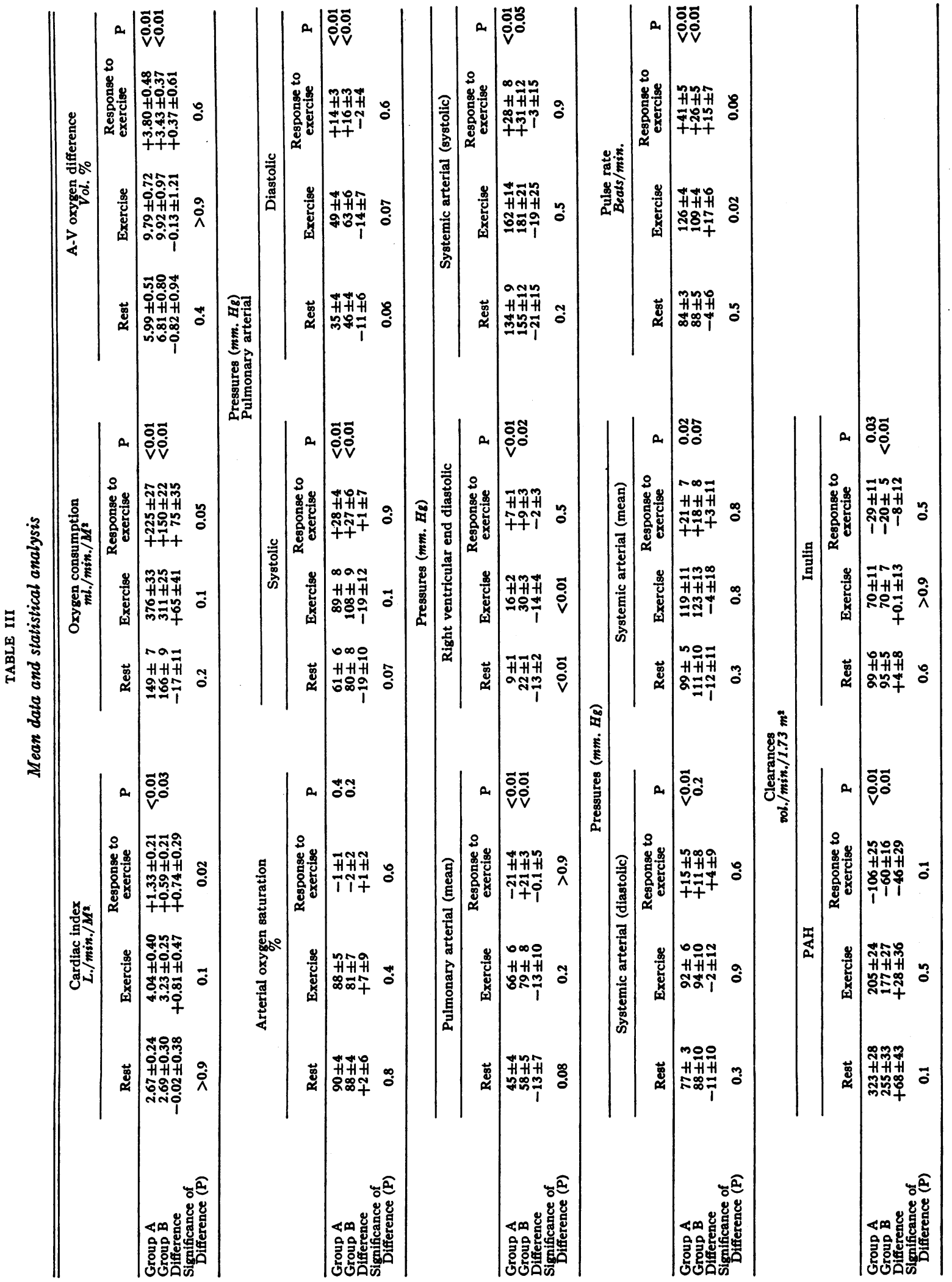


difference, but was associated with a significantly larger increase in oxygen consumption in the edema free than in the edematous group. Two cardiac patients without edema (D. C. and A. C.) who clinically had much less cardiac insufficiency than the rest of the patients in the study exercised so vigorously that they had by far the largest increases in oxygen consumption. If these two patients are excluded from the statistical analysis, the differences in both cardiac index and oxygen consumption between the groups in response to exercise lack statistical significance, the $P$ values being .07 and .2 , respectively. The arterial oxygen saturation at rest, during exercise and the changes in response to exercise did not differ significantly between the two groups. Although this measurement was reduced at rest, it did not change significantly with exercise.

Pulmonary arterial pressure. At rest and during exercise, the average systolic, diastolic and mean pulmonary arterial pressures were elevated in both groups, but were 11 to $19 \mathrm{~mm}$. $\mathrm{Hg}$ lower in the group without edema than in the group with edema. The differences between the groups, however, lacked statistical significance at the 5 per cent level. The significant increases in pulmonary arterial pressures which occurred in both groups in response to exercise, were not significantly different from each other.

Right ventricular end-diastolic pressure. In the cardiac group without edema the right ventricular end-diastolic pressure at rest was slightly elevated whereas in the edematous group it was strikingly elevated. The difference was highly significant statistically. During exercise likewise the right ventricular end-diastolic pressure was significantly higher in the group with edema than the group without edema. In response to exercise both groups had significant increases in the right ventricular end-diastolic pressure which were not significantly different from each other.

Systemic arterial pressure. The average systolic, diastolic and mean arterial pressures at rest, during exercise and the changes in response to exercise were not significantly different between the groups. The increases in all of the components of the systemic arterial pressure were significant only in the non-edematous cardiac group.

Pulse rate. Statistical analysis showed that the pulse rates, which were not significantly different at rest, were significantly higher during exercise in the non-edematous than in the edematous group. The rise in pulse rate in response to exercise, however, just lacked being significantly different in the two groups.

\section{Renal clearance measurements}

$P A H$ clearance. In both cardiac groups the renal plasma flow was reduced at rest. In response to exercise both groups had further decreases in this function which were statistically significant. The average $\mathrm{PAH}$ clearances at rest and during exercise were respectively $68 \mathrm{ml}$. per $\min$. per $1.73 \mathrm{~m}^{2}$ and $28 \mathrm{ml}$. per min. per $1.73 \mathrm{~m}^{2}$ higher in the group without edema than in the group with edema. However, these differences between the groups (both at rest and during exercise) lacked statistical significance.

Inulin clearance. In both cardiac groups the glomerular filtration rate, which was reduced at rest, was significantly further depressed during exercise. The inulin clearance at rest, during exercise, and the change in response to exercise were not significantly different between the groups.

\section{DISCUSSION}

Cardiac patients with signs and symptoms of pulmonary congestion but with little or no evidence of "right-sided heart failure" do not necessarily develop salt and fluid retention when placed on a moderately high sodium intake. A majority of such patients, most of whom had valvular heart disease, were also found to have no obvious defect in the excretion of sodium when loaded acutely with hypertonic saline. Past studies, however, indicate that cardiac patients with previous "right sided failure" may have a persistent disturbance in sodium excretion even after "compensation" $(2,5)$. Since in the present study sodium excretion was determined only in cardiac patients without a history of peripheral edema, the previous findings do not necessarily conflict with the present results.

A number of the cardiac patients who tolerated a moderately high salt diet without developing edema had many hemodynamic as well as clinical findings considered to be indicative of severe cardiac insufficiency. In addition to pulmonary hypertension, their circulatory abnormalities included a reduction in cardiac output and a de- 
crease in renal plasma flow and glomerular filtration rate. However, in none was the right ventricular end-diastolic pressure elevated above 14 $\mathrm{mm} . \mathrm{Hg}$. This latter hemodynamic function was the most consistent one which differentiated the cardiac group who had no evidence of salt and water retention from the group with such retention as indicated by the clinical finding of peripheral edema. In every one of the "salt-retaining group" right ventricular end-diastolic pressure was above $15 \mathrm{~mm} . \mathrm{Hg}$. Neither at rest nor during exercise were the cardiac output, pulmonary artery pressure, systemic arterial pressure, renal plasma flow and glomerular filtration rate consistently or significantly different in the two groups.

The present findings do not lend support to the "forward failure" concept as the predominant cause of edema formation in congestive heart failure. Rather they are more consistent with the "backward failure" concept in that they suggest that a critical elevation of the right ventricular end-diastolic pressure and peripheral venous pressure is the more important determining factor. However, it is obviously possible that reductions in cardiac output and glomerular filtration rate may also operate to increase the renal retention of sodium and water. Studies in experimentally induced heart failure also indicate that retention of salt and water occurs primarily as a result of the elevation of the venous pressure $(6,7)$.

Although venous hypertension may signal the danger of edema formation in congestive heart failure, edema may not form without an ample dietary intake of sodium chloride. A number of cardiac patients, while having a marked and persistent elevation of the venous pressure, have been observed to be edema free during a restricted intake of sodium. However, on increasing the sodium intake, these patients have developed salt retention and peripheral edema. The studies of Relman and Schwartz (8) may have a bearing on these observations in that they suggest that the action of salt retaining hormones, which appear to be increased in congestive heart failure $(9,10)$ are affected by the sodium content of diet.

\section{SUMMARY}

Cardiac patients who had many clinical and hemodynamic findings of congestive heart failure but no history of peripheral edema were found to tolerate a moderately high sodium intake without developing edema or salt retention. Many in the group likewise showed no impairment in sodium excretion when infused with 5 per cent saline. The most consistent hemodynamic measurement that differentiated this group from a similar cardiac group with peripheral edema was the finding of a lower right ventricular end-diastolic pressure. This finding supports the concept that salt retention in congestive heart failure may be initiated primarily by a critical rise in the venous pressure rather than by a decrease in cardiac output or glomerular filtration rate.

\section{REFERENCES}

1. Futcher, P. H., and Schroeder, H. A., Studies on congestive heart failure; II. Impaired renal excretion of sodium chloride. Am. J. M. Sc., 1942, 204, 52.

2. Proger, S., Ginsberg, E., and Magendantz, H., The effects of the ingestion of excessive amounts of sodium chloride and water on patients with heart disease. Am. Heart J., 1942, 23, 555.

3. Judson, W. E., Hatcher, J. D., Hollander, W., and Halperin, M. H., The effects of mitral valvuloplasty on cardiovascular and renal function at rest and during exercise. J. Clin. Invest., 1955, 34, 1297.

4. Wilson, D. W., and Ball, E. G., A study of the estimation of chloride in blood and serum. J. Biol. Chem., 1928, 79, 221.

5. Warren, J. V., and Stead, E. A., Jr., Fluid dynamics in chronic congestive heart failure; an interpretation of the mechanisms producing the edema, increased plasma volume and elevated venous pressure in certain patients with prolonged congestive failure. Arch. Int. Med., 1944, 73, 138.

6. Fishman, A. P., Stamler, J., Katz, L. N., Miller, A. J., Silber, E. N., and Rubenstein, L., Mechanisms of edema formation in chronic experimental pericarditis with effusion. J. Clin. Invest., 1950, 29, 521.

7. Davis, J. O., Hyatt, R. E., and Howell, D. S., Rightsided congestive heart failure in dogs produced by controlled progressive constriction of the pulmonary artery. Circ. Research, 1955, 3, 252.

8. Relman, A. S., and Schwartz, W. B., The effect of DOCA on electrolyte balance in normal man and its relation to sodium chloride intake. Yale J. Biol. \& Med., 1952, 24, 540.

9. Deming, Q. B., and Luetscher, J. A., Jr., Bioassay of desoxycorticosterone-like material in urine. Proc. Soc. Exper. Biol. \& Med., 1950, 73, 171.

10. Parrish, A. E., The bioassay of adrenal corticoids in the urine of patients with congestive heart failure. J. Clin. Invest., 1949, 28, 45. 